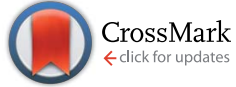

Cite this: RSC Adv., 2017, 7, 2407

Received 3rd November 2016 Accepted 14th December 2016

DOI: $10.1039 / c 6 r a 26247 c$

www.rsc.org/advances

\title{
Novel core-shell structured Si/S-doped-carbon composite with buffering voids as high performance anode for Li-ion batteries
}

\begin{abstract}
Dan Shao, ${ }^{\text {ab }}$ Inna Smolianova, ${ }^{\text {ac }}$ Daoping Tang ${ }^{a}$ and Lingzhi Zhang ${ }^{\star a}$
A novel core-shell structured Si/S-doped-carbon composite with buffering voids (Si/v-SC), was prepared by a facile hydrothermal method using glucose as carbon source and simultaneously chemical polymerization of 3,4-ethylenedioxythiophene (EDOT) in the presence of $\mathrm{SiaSiO}_{2}$ nanoparticles, and followed by carbonization and removal of the $\mathrm{SiO}_{2}$ layer. The results showed that the Si nanoparticles were embedded in the S-doped-carbon buffer space to form a core-shell structure. Compared to the $\mathrm{Si} /$ carbon composite (Si/v-C) without S-doping in carbon layer, the Si/v-SC composite electrode showed improved cycling and rate performance, exhibiting a reversible capacity of $664 \mathrm{~mA} \mathrm{~h} \mathrm{~g}^{-1}$ over 300 cycles at the current of $0.4 \mathrm{~A} \mathrm{~g}^{-1}$ and a high capacity of $537 \mathrm{~mA} \mathrm{~h} \mathrm{~g}^{-1}$ even at $10 \mathrm{~A} \mathrm{~g}^{-1}$. The effects of S-doping on the properties of carbon material were further investigated. XRD and Raman test revealed that the Sdoping increased the interspace of carbon crystal face, and improved the amorphous structure of carbon and thus the initial coulombic efficiency.
\end{abstract}

\section{Introduction}

Silicon ( $\mathrm{Si}$ ) is one of the most promising next generation anode materials for lithium-ion batteries (LIBs) due to its ultrahigh theoretical capacity ( $4200 \mathrm{~mA} \mathrm{~h} \mathrm{~g}{ }^{-1}$ ) and the low Li-uptake potential. ${ }^{1-6}$ Unfortunately, the major obstacles to the practical use in LIBs for Si anode are its low intrinsic electrical conductivity and the severe volume change $(400 \%)$ during the lithiation and delithiation processes which lead to the pulverization of Si active particles, unstable solid electrolyte interface film (SEI) on the surface of the Si anode and consequently causes rapid capacity decay of the cell. ${ }^{1-7}$

Carbon is usually used as a matrix in the $\mathrm{Si} /$ carbon composites, aiming to utilize the good flexibility, conductivity and SEI formation ability of carbon component. ${ }^{8-10}$ The carbon matrix can not only act as conductive medium to compensate for the intrinsic low conductivity of Si component, but also accommodate the large volume variation of Si particles over cycling, thus improving the cycle stability and rate capability. ${ }^{11,12}$ Unfortunately, because of insufficient internal volume for accommodating the severe volume change of Si particles, especially over long cycling at high current density, these conventional Si/carbon composites show limited success for the use of anode materials in LIBs. ${ }^{13,14}$ Creating suitable voids between the carbon layer and $\mathrm{Si}$ particles in $\mathrm{Si} /$ carbon

${ }^{a}$ Key Laboratory of Renewable Energy, Guangzhou Institute of Energy Conversion,
Chinese Academy of Sciences, Guangzhou 510640, China
${ }^{b}$ Guangzhou Institute of Energy Testing, Guangzhou 510170, China
${ }^{c}$ University of Chinese Academy of Sciences, 19 Yu Quan Road, Beijing, 100049, China composite facilitates to further buffer the volume variation of $\mathrm{Si}$ is one of effective methods to overcome this problem. ${ }^{15-17}$ Previously, we also reported a novel Si/porous-C composite with buffering voids. ${ }^{18}$ However, the carbon components in these Si composites usually cause a large irreversible capacity loss during the first cycle and correspondingly a low initial coulombic efficiency (CE), which limits the practical use of these $\mathrm{Si} /$ carbon composites in industry. ${ }^{18}$

Heteroatom such as S- and N-doped carbon as anode materials of LIBs have shown high lithiation capacity (even exceeding the theoretical capacity of graphitic carbon anode) and longer cycling life. ${ }^{19,20}$ We previously reported Si/3,4-ethylenedioxythiophene:poly(styrenesulfonate) (PEDOT:PSS) and Si/Sdoped-carbon composite as anode materials which exhibited extraordinary high CE. ${ }^{21,22}$ However, the cycling stability of these composites is not satisfied enough for the practical applications, due to the poor distribution of Si particles and the insufficient internal volume in the composite for accommodating the severe volume variation.

In this paper, a novel silicon/S-doped carbon composite, core-shell structured Si/S-doped carbon composite with buffering voids $(\mathrm{Si} / \mathrm{v}-\mathrm{SC})$, was prepared by a facile hydrothermal method in the presence of $\mathrm{Si}$ nanoparticles, followed by a carbonizing process and subsequent removal of $\mathrm{SiO}_{2}$ template. The structural characterization and electrochemical properties of the composite have been investigated in detail. The effects of S-doping on the properties of carbon materials without coupling with Si nanoparticles were comparably investigated as a simplifying system. 


\section{Experiment}

Materials

Si nanoparticles were purchased from Xuzhou Jie chuang New Material Technology Company. EDOT (99\%) was purchased from Sigma-Aldrich Company. PSS (MW: 70 000) was purchased from Acros Organics. Glucose (>99\%), $\mathrm{Fe}_{2}\left(\mathrm{SO}_{4}\right)_{3}(>99 \%)$ and $\left(\mathrm{NH}_{4}\right) \mathrm{S}_{2} \mathrm{O}_{8}$ $(>98 \%)$ were obtained from Tianjin Fuchen Chemicals Reagent Factory. Hydrofluoric acid (HF) $(\geq 40 \%)$ was purchased from Guangzhou Chemicals Reagent Company. The electrolyte of $1 \mathrm{M}$ $\mathrm{LiPF}_{6}$ and $5 \%$ fluoroethylene carbonate (FEC) in ethylene carbonate $(\mathrm{EC},>99.9 \%$ )/diethylene carbonate (DEC, >99.9\%)/ dimethyl carbonate (DMC, >99.9\%) (v/v/v = $1: 1: 1$, water content $<20 \mathrm{ppm}$ ) was purchased from Zhangjiagang Guotai Huarong New Chemical Materials Company. All chemicals were used as received. The Celgard 2400 was employed as a separator.

\section{Preparation of $\mathrm{Si} / \mathrm{v}-\mathrm{SC}$ composite}

$\mathrm{Si} / \mathrm{v}$-SC was prepared by a facile hydrothermal method using glucose as carbon source and simultaneously chemical polymerization of 3,4-ethylenedioxythiophene (EDOT) as sulfur source in the presence of $\mathrm{Si} @ \mathrm{SiO}_{2}$ nanoparticles which obtained after oxidation of Si nanoparticles, followed by carbonization and removal of the $\mathrm{SiO}_{2}$ layer. The schematic fabrication process of $\mathrm{Si} / \mathrm{v}$-SC was illustrated in Fig. 1. In a typical procedure, Si nanoparticles ( $0.3 \mathrm{~g}$ ) was calcined in an air atmosphere at $600{ }^{\circ} \mathrm{C}$ for $3 \mathrm{~h}$ to form a layer of $\mathrm{SiO}_{2}$ coating on the surface to get $\mathrm{Si@SiO} \mathrm{S}_{2}$ nanoparticles (0.35 g). EDOT ( $\left.0.3 \mathrm{~g}\right)$ was added to a solution of PSS $(0.58 \mathrm{~g})$ in $30 \mathrm{~mL}$ deionized water, and stirred further for $2 \mathrm{~h}$. Glucose $(1 \mathrm{~g})$ was then added into the above solution. After stirring for $2 \mathrm{~h}$, the catalyst solution of $\left(\mathrm{NH}_{4}\right) \mathrm{S}_{2} \mathrm{O}_{8}$ $(0.5 \mathrm{~g}) / \mathrm{Fe}_{2}\left(\mathrm{SO}_{4}\right)_{3}(2 \mathrm{mg})$ was then added to the reaction mixture. In this solution, $\mathrm{Si} @ \mathrm{SiO}_{2}$ nanoparticles (0.35 g) was added and dispersed by sonication for $2 \mathrm{~h}$. This suspension was then heattreated in a sealed steel autoclave at $150{ }^{\circ} \mathrm{C}$ for $6 \mathrm{~h}$ under an $\mathrm{Ar}$ atmosphere at a heating rate of $3{ }^{\circ} \mathrm{C} \mathrm{min}^{-1}$. A solid precipitate (noted as Si/v-SC-P) was recovered, washed with water/ethanol, dried under vacuum at $60{ }^{\circ} \mathrm{C}$ for $24 \mathrm{~h}$, and then calcined at $800{ }^{\circ} \mathrm{C}$ for $3 \mathrm{~h}$ under $\mathrm{Ar}$ atmosphere. The obtained composite

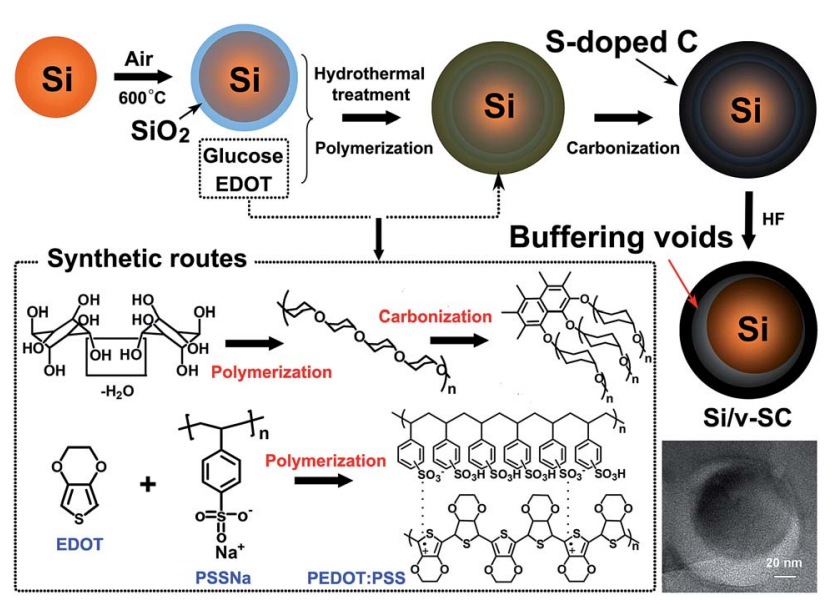

Fig. 1 Schematic mechanism for the synthesis of Si/v-SC. was then treated with $10 \mathrm{wt} \% \mathrm{HF}$ solution for $2 \mathrm{~h}$ to remove the $\mathrm{SiO}_{2}$ layer. The final product of $\mathrm{Si} / \mathrm{v}-\mathrm{SC}$ composite was dried under vacuum at $60{ }^{\circ} \mathrm{C}$ for $24 \mathrm{~h}$ after centrifugation and washing with water/ethanol. As comparison, $\mathrm{Si} /$ carbon composite with buffering voids composite $(\mathrm{Si} / \mathrm{v}-\mathrm{C})$ was prepared through the same method without the S-containing EDOT, PSS and $\left(\mathrm{NH}_{4}\right)$ $\mathrm{S}_{2} \mathrm{O}_{8} / \mathrm{Fe}_{2}\left(\mathrm{SO}_{4}\right)_{3}$.

In order to investigate the effects of S-doping on the properties of carbon matrix, S-doped carbon materials with different S-doping contents were prepared. EDOT (0, 0.05, 0.1, 0.2, $0.3 \mathrm{~g}$ ) was added to a solution of PSS $(0,0.1,0.2,0.4,0.6 \mathrm{~g})$ in $30 \mathrm{~mL}$ deionized water, respectively, and stirred further for $2 \mathrm{~h}$. Glucose $(1 \mathrm{~g})$ was then added into the above solution. After stirring for $2 \mathrm{~h}$, the catalyst solution of $\left(\mathrm{NH}_{4}\right) \mathrm{S}_{2} \mathrm{O}_{8}(0,0.08,0.16,0.33,0.5 \mathrm{~g}) /$ $\mathrm{Fe}_{2}\left(\mathrm{SO}_{4}\right)_{3}(0,0.32,0.64,1.32,2 \mathrm{mg})$ was then added in the corresponding solution. The suspension was then heat-treated in a sealed steel autoclave at $150{ }^{\circ} \mathrm{C}$ for $6 \mathrm{~h}$ at a heating rate of $3{ }^{\circ} \mathrm{C}$ $\min ^{-1}$. Solid precipitate was recovered, washed with water/ ethanol, dried under vacuum at $60{ }^{\circ} \mathrm{C}$ for $24 \mathrm{~h}$, and then calcined at $800{ }^{\circ} \mathrm{C}$ for $3 \mathrm{~h}$ under $\mathrm{Ar}$ gas protection. The obtained product noted as SC-1, SC-2, SC-3, SC-4 and SC-5, respectively.

\section{Characterization}

Fourier transform infrared spectra (FTIR) were carried out on a tensor 27 spectrometer from 4000 to $400 \mathrm{~cm}^{-1}$ (Bruker, Germany). The morphology and microstructure of samples were characterized by transmission electron microscope (TEM) (JEOL JEM 2100F, Japan) and scanning electron microscope (SEM) (Hitachi S-4800, Japan). The conductivity of the products was measured through 2-wire Ohms method using the IM6e electrochemical workstation (Zahner, Germany) at $25{ }^{\circ} \mathrm{C}$. The crystal structures and composition of samples were studied by $\mathrm{X}$-ray diffraction (XRD) (PANALYTICAL, the Netherlands) and HR800 Confocal Raman system (HORIBA Jobin Yvon, France). The XPS spectra were obtained with ESCALAB250 XPS (Thermo Fisher Scientific, USA) at $2 \times 10^{-9}$ mbar, using Al K $(1486.6 \mathrm{eV})$ radiation at $15 \mathrm{keV}$ of anode voltage. Thermogravimetric analysis measurements (TGA) were carried out on a STA409C/PCPFEIFFER VACUUMTGA-7 analyzer (NETZSCH-Gertebau $\mathrm{GmbH}$, Germany) in either air or an Ar atmosphere with a flow rate of $30 \mathrm{~mL} \mathrm{~min}{ }^{-1}$ from $30{ }^{\circ} \mathrm{C}$ to $800{ }^{\circ} \mathrm{C}$.

\section{Electrochemical measurement}

Electrochemical measurements of samples were performed by coin-type half cells (CR2025) that were assembled in an Ar-filled glovebox. The working electrode were constructed as follows: $70 \mathrm{wt} \%$ active material, $20 \mathrm{wt} \%$ carbon black and $10 \mathrm{wt} \%$ carboxymethyl cellulose in an aqueous solution were mixed, and the slurry was coated on a copper foil at room temperature and dried under vacuum at $60{ }^{\circ} \mathrm{C}$ overnight and then pressed to obtain the electrode sheets. The loading level of the active material is $0.7,0.4$ and $0.5 \mathrm{mg} \mathrm{cm}^{-2}$ for $\mathrm{Si}, \mathrm{Si} / \mathrm{v}-\mathrm{C}$ and $\mathrm{Si} / \mathrm{v}-\mathrm{SC}$ electrode, respectively. The counter electrode was Li foil, the separator was Celgard 2400 and the electrolyte solution was

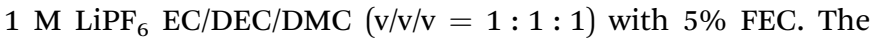
cells were aged for $24 \mathrm{~h}$ before further measurements. A 
galvanostatic cycling test of the assembled cells was carried out on a Shenzhen Neware battery cycler (China) at various rates between cut-off voltages of 0.01 and $1.5 \mathrm{~V}\left(v s . \mathrm{Li} / \mathrm{Li}^{+}\right)$at $25{ }^{\circ} \mathrm{C}$. Electrochemical impedance spectroscopic (EIS) and cyclic voltammetry (CV) measurements were recorded on an IM6e electrochemical workstation (Zahner, Germany). EIS was measured by applying an oscillating voltage of $5 \mathrm{mV}$ over the frequency ranging from $10^{-2}$ to $10^{5} \mathrm{~Hz}$. $\mathrm{CV}$ was conducted in cells at different scan rates from $10 \mathrm{mV}$ to $1.5 \mathrm{~V}$.

\section{Results and discussion}

\section{Structural characterization}

Fourier transform infrared (FTIR) spectroscopy was used to characterize the formation of the $\mathrm{Si} / \mathrm{v}$-SC including the hydrothermal and carbonization process. As shown in Fig. 2a, the FTIR characteristic peak of $\mathrm{C}=\mathrm{O} / \mathrm{C}=\mathrm{C}$ vibration band at 1705 / $1620 \mathrm{~cm}^{-1}$ in spectra of $\mathrm{Si} / \mathrm{v}-\mathrm{SC}-\mathrm{P}$ confirmed the dehydration of glucose during the hydrothermal process. ${ }^{13}$ For Si/v-SC-P, the $=$ $\mathrm{C}-\mathrm{H}$ deformation vibration peak of EDOT at $891 \mathrm{~cm}^{-1}$ disappeared. The $-\mathrm{C}-\mathrm{S}-$ bond at $980 \mathrm{~cm}^{-1}$, the stretching vibration of the $-\mathrm{C}-\mathrm{O}-\mathrm{C}-$ bond at $1090 \mathrm{~cm}^{-1}$, and the $\mathrm{C}-\mathrm{C}$ and $\mathrm{C}=\mathrm{C}$ stretches from thiophene ring at $1335 \mathrm{~cm}^{-1}$ appeared correspondingly, confirming the successful polymerization of 3,4ethylenedioxythiophene (EDOT). For Si/v-SC, the typical bands of the thiophene ring at $1335 \mathrm{~cm}^{-1}$ from PEDOT disappeared, indicating that PEDOT was completely transformed into carbon after carbonization process. ${ }^{21}$ The content of $\mathrm{Si}$ and carbon in the $\mathrm{Si} / \mathrm{v}$-SC composite is estimated to be 61.7 and $38.3 \mathrm{wt} \%$, based on the thermal gravimetric curves, respectively (Fig. 2b).

XRD and Raman measurement were conducted to further examine the structures of these samples. All of $\mathrm{Si}, \mathrm{Si} / \mathrm{v}-\mathrm{SC}-\mathrm{P}$ and $\mathrm{Si} / \mathrm{v}$-SC showed the characteristic diffraction peaks of $\mathrm{Si}$ at $2 \theta$ of about $28.4^{\circ}, 47.4^{\circ}, 56.2^{\circ}, 69.2^{\circ}$ and $76.5^{\circ}$, corresponding to the (111), (220), (311), (400) and (331) planes of Si crystals (JCPDS no. 27-1402), respectively (Fig. 3a). ${ }^{23,24}$ The peaks of Si remained indicate that the high temperature hydrothermal reaction and the followed carbonization process did not change the crystal structure of Si. For Si/v-SC, two weak and broad diffraction peaks were observed at about $23^{\circ}$ and $43^{\circ}$ corresponding to the amorphous carbon in the composite (Fig. 3a(i) and (ii)). ${ }^{25}$ Raman spectra of $\mathrm{Si}, \mathrm{Si} / \mathrm{v}-\mathrm{SC}-\mathrm{P}$ and $\mathrm{Si} / \mathrm{v}$-SC were presented in Fig. $3 \mathrm{~b}$. For

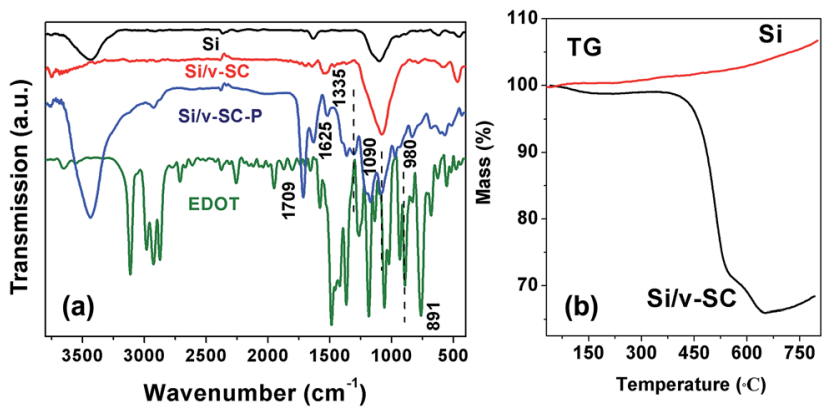

Fig. 2 FTIR spectra of EDOT, Si, Si/v-SC-P and Si/v-SC (a). TG curves of $\mathrm{Si}$ and $\mathrm{Si} / \mathrm{v}-\mathrm{SC}$ under $\mathrm{Ar}$ atmospheres (b).
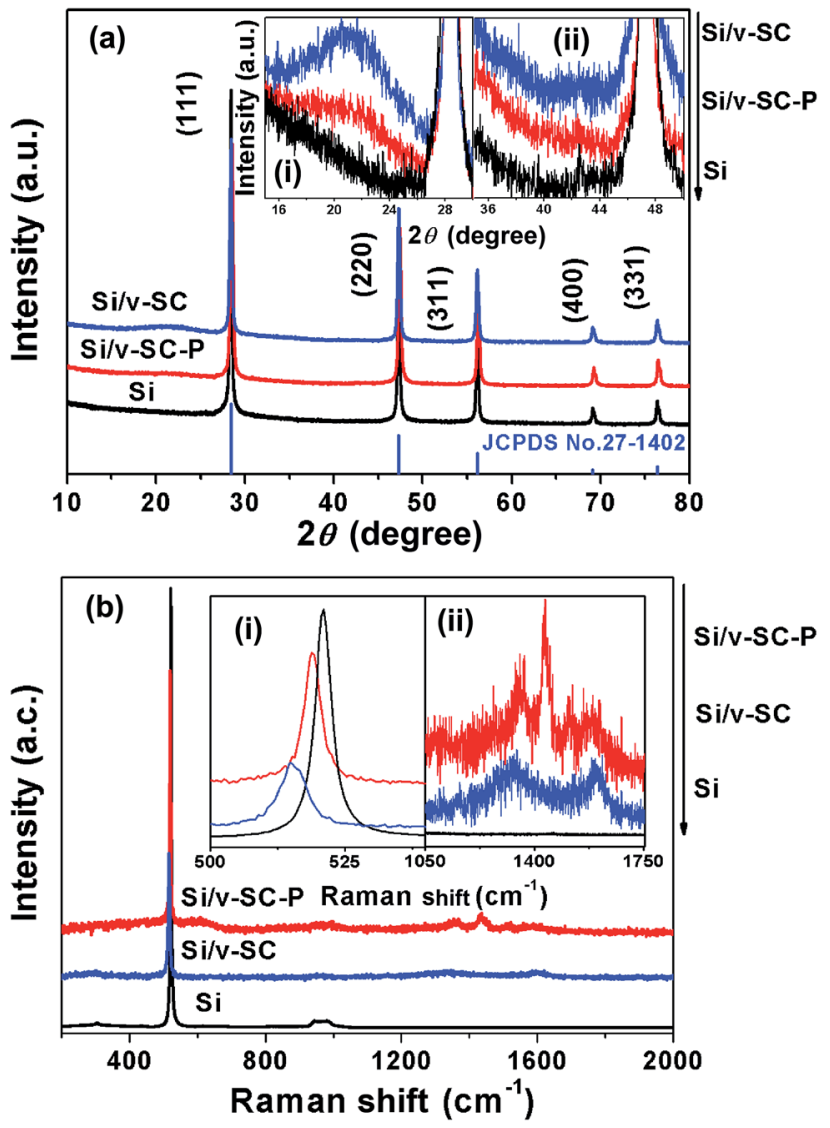

Fig. 3 XRD patterns of $\mathrm{Si}, \mathrm{Si} / \mathrm{v}-\mathrm{SC}-\mathrm{P}$ and $\mathrm{Si} / \mathrm{v}-\mathrm{SC}$ (a), and partial magnification XRD patterns of the samples (a, insert). Raman spectrum of $\mathrm{Si}, \mathrm{Si} / \mathrm{v}-\mathrm{SC}-\mathrm{P}$ and $\mathrm{Si} / \mathrm{v}-\mathrm{SC}$ (b), and partial magnification Raman shift of the samples (b, insert).

all these samples, the characteristic peaks of Si were observed at 295, 520 and $940 \mathrm{~cm}^{-1}$. For both Si/v-SC-P and Si/v-SC, the peak at around $520 \mathrm{~cm}^{-1}$ was somewhat broadened and downshifted to lower wavenumber compared with $\mathrm{Si}$ (Fig. 3b(i)), probably due to a masking effect induced by carbon coating layer. ${ }^{13}$ For Si/vSC-P, the characteristic peaks of PEDOT, the $\mathrm{C}-\mathrm{C}$ inter-ring stretching vibration at $1267 \mathrm{~cm}^{-1}$, the $\mathrm{C}=\mathrm{C}$ symmetrical/ asymmetrical stretching vibration at $1433 / 1510 \mathrm{~cm}^{-1}$, were clearly observed (Fig. 3b(ii)). ${ }^{26}$ After carbonization, these characteristic peaks of PEDOT disappeared for $\mathrm{Si} / \mathrm{v}$-SC sample. The weak peaks at 1340 and $1580 \mathrm{~cm}^{-1}$ corresponding to the $\mathrm{D}$ and $\mathrm{G}$ band of carbon component, typical for amorphous carbon and crystalline graphite, were observed for Si/v-SC (Fig. 3b(ii)). ${ }^{24}$

From SEM and TEM images of Si nanoparticles, the particle size of the bare Si nanoparticle ranges from 30 to $80 \mathrm{~nm}$ with a spherical shape (Fig. 4a and b). Fig. 4c showed that the $\mathrm{Si} @ \mathrm{SiO}_{2}$ nanoparticle ranged from 50 to $100 \mathrm{~nm}$ with a spherical shape, covered with a $10 \mathrm{~nm}$ thick $\mathrm{SiO}_{2}$ layer (Fig. 4c inset). The Si/v-SC-P composite consisted of the amorphous carbon coated $\mathrm{Si} @ \mathrm{SiO}_{2}$ (Fig. 4d). After the carbonization process and removal of $\mathrm{SiO}_{2}$ layer, a 10-12 nm thick space surrounded with $\mathrm{Si}$ nanoparticles was observed clearly for Si/v-SC (Fig. 5a). Consistent with the SEM result, TEM image also showed that the Si nanoparticles in $\mathrm{Si} / \mathrm{v}-\mathrm{SC}$ were buried in the carbon shell 

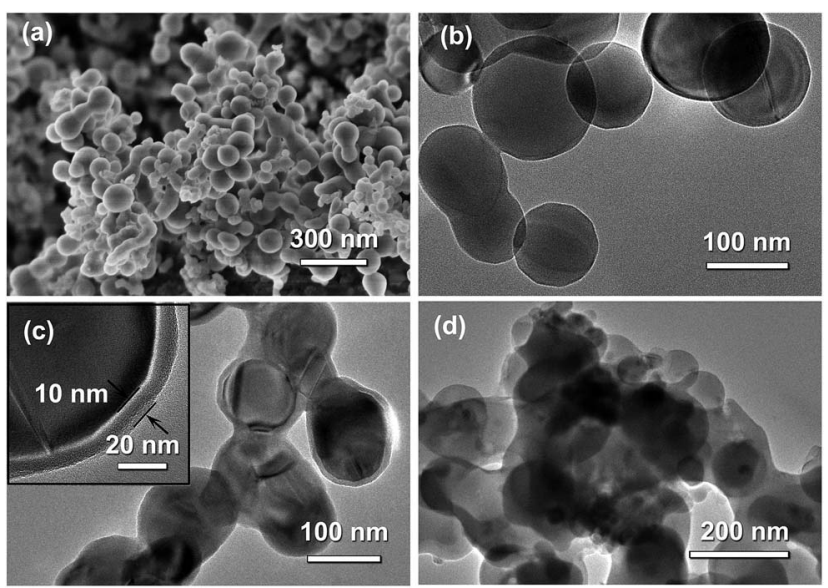

Fig. 4 SEM image (a) and TEM image (b) of Si nanoparticles. TEM image of $\mathrm{Si@SiO}$ (c) and Si/v-SC-P (d) particles.
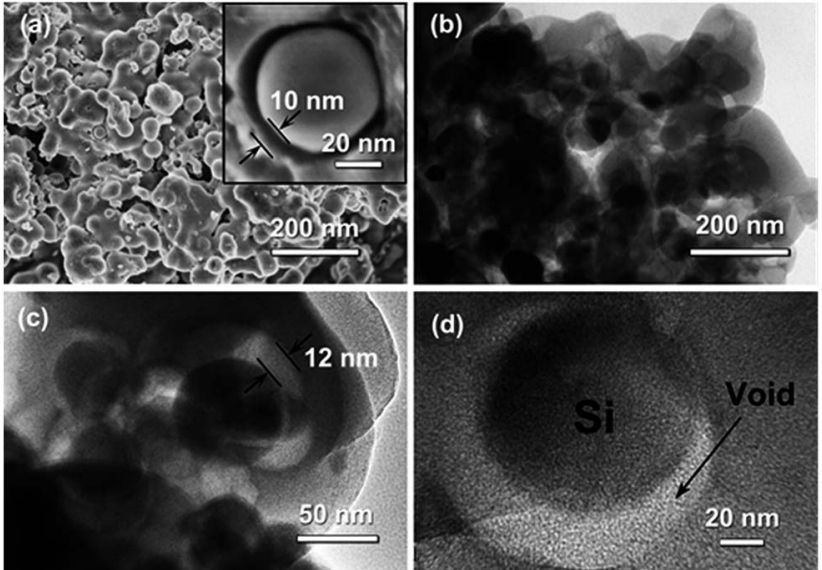

Fig. 5 SEM image (a) and TEM image $(b-d)$ of Si/v-SC particles.

with buffering voids (Fig. 5b-d). SEM examination combined with EDS mapping for the elements $\mathrm{Si}, \mathrm{C}$ and $\mathrm{S}$ are provided in Fig. 6. EDS analysis showed that the weight ratio of $\mathrm{S}$ in the $\mathrm{Si} / \mathrm{v}$ SC composite was $2 \mathrm{wt} \%$ (Fig. 6). For Si/v-SC, $5.2 \mathrm{wt} \%$ of the S element was doped in the carbon component in the $\mathrm{Si} / \mathrm{v}-\mathrm{SC}$ composite. The bright regions are relevant to the presence of the elements $\mathrm{Si}, \mathrm{C}$ and $\mathrm{S}$, indicating that $\mathrm{S}$ and $\mathrm{C}$ are distributed homogenously covered the Si nanoparticles (Fig. 6b-d).

XPS experiments were used to investigate the bonding state of $\mathrm{C}$ and $\mathrm{S}$ atom in Si/v-SC composite (Fig. 7). The $\mathrm{C}$ 1s spectrum is composed of three peaks at the binding energies of $284.6 \mathrm{eV}$, $285.7 \mathrm{eV}$ and $286.5 \mathrm{eV}$, the first two peaks corresponding to $\mathrm{C}$ atoms with $\mathrm{sp}^{2}$ hybridization and $\mathrm{sp}^{3}$ hybridization and the third peak at higher binding energy corresponding to $\mathrm{C}-\mathrm{S} .{ }^{27}$ The $S$ 2p spectrum shows three main peaks at 164.0, 165.1 and $168.5 \mathrm{eV}$, corresponding to the sulphide bridge $(-\mathrm{C}-\mathrm{S}-\mathrm{C}-)$ for the first two peaks and to the sulphone bridge $\left(-\mathrm{C}-\mathrm{SO}_{2}-\mathrm{C}-\right)$ for the third peak. ${ }^{27,28}$ The sulphide bridge form of the doped sulfur in the amorphous carbon anode can increase the lithiation capacity of the cells, which may have a favorable effect on improving the electrochemical performance of Si/v-SC. ${ }^{21}$

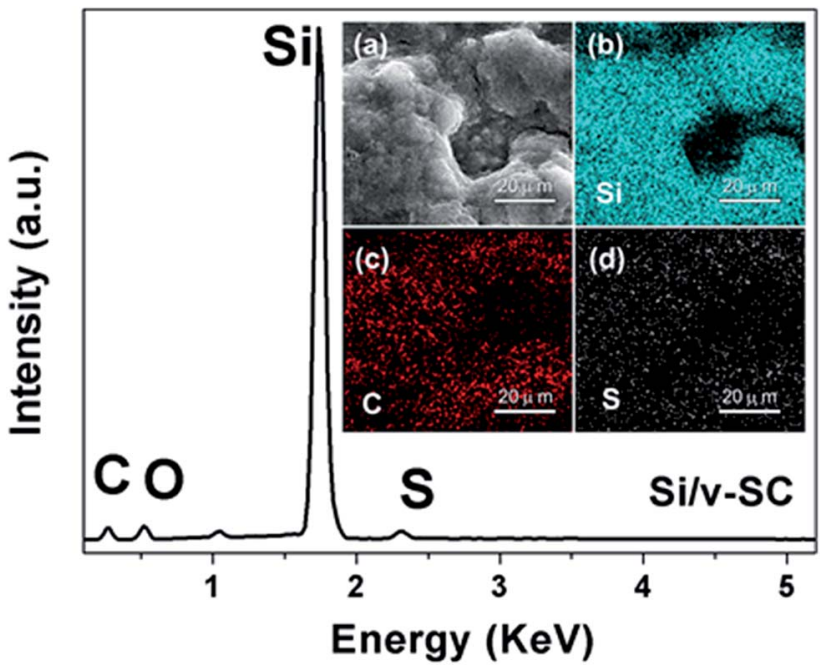

Fig. 6 EDS spectra of Si/v-SC, and cross-sectional SEM image of Si/vSC (insert, a), with corresponding EDS mapping of silicon (b) and (c) carbon and sulfur (d).

Electrical conductivities of $\mathrm{Si}, \mathrm{Si} / \mathrm{v}-\mathrm{C}$ and $\mathrm{Si} / \mathrm{v}-\mathrm{SC}$ were measured by employing 2-wire Ohms measurement apparatus (Fig. 8). Compared with Si sample $\left(2.7 \times 10^{-6} \mathrm{~S} \mathrm{~cm}^{-1}\right)$, the composite samples exhibited higher conductivities due to the electrically conductive carbon component. Specifically, the conductivity of $\mathrm{Si} / \mathrm{v}-\mathrm{SC}$ sample $\left(10.7 \mathrm{~S} \mathrm{~cm}^{-1}\right)$ is higher than that of $\mathrm{Si} / \mathrm{v}-\mathrm{C}\left(3.1 \mathrm{~S} \mathrm{~cm}^{-1}\right)$, indicating that the S-doping increases the conductivity of the composite.

\section{Electrochemical characterization}

The initial voltage profile for $\mathrm{Si}, \mathrm{Si} / \mathrm{v}-\mathrm{C}$ and $\mathrm{Si} / \mathrm{v}-\mathrm{SC}$ showed a typical lithiation/delithiation plateau of $\mathrm{Si}$ around 0.15 and $0.4 \mathrm{~V}$ (Fig. 9a). ${ }^{29-31}$ Whereas, $\mathrm{Si} / \mathrm{v}-\mathrm{C}$ and $\mathrm{Si} / \mathrm{v}-\mathrm{SC}$ samples exhibited a short charge plateau at about $0.75 \mathrm{~V}$ during the first

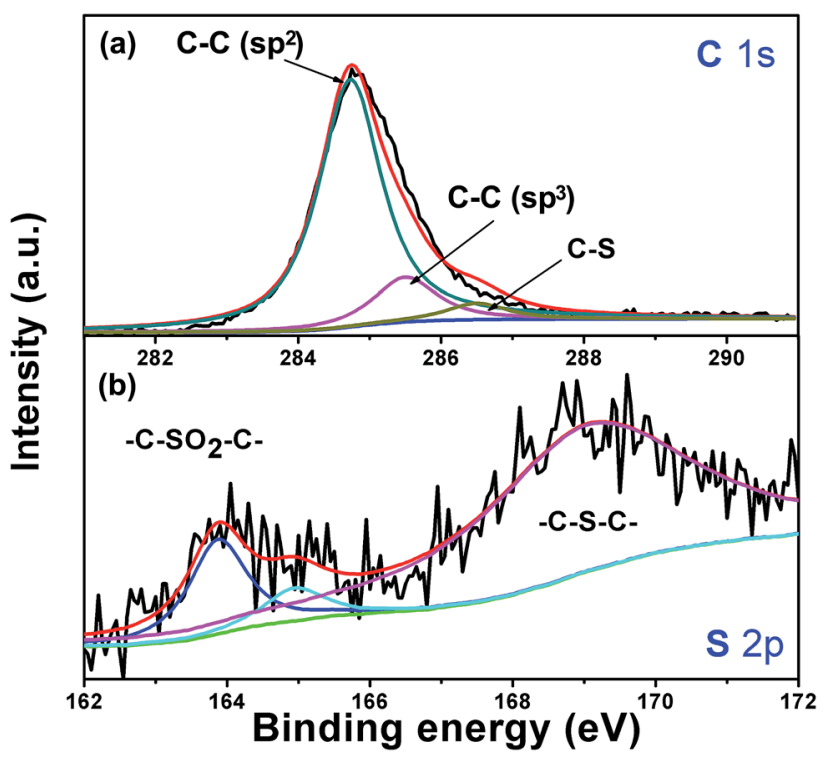

Fig. 7 C 1s (a) and S 2p (b) XPS spectra of Si/v-SC. 


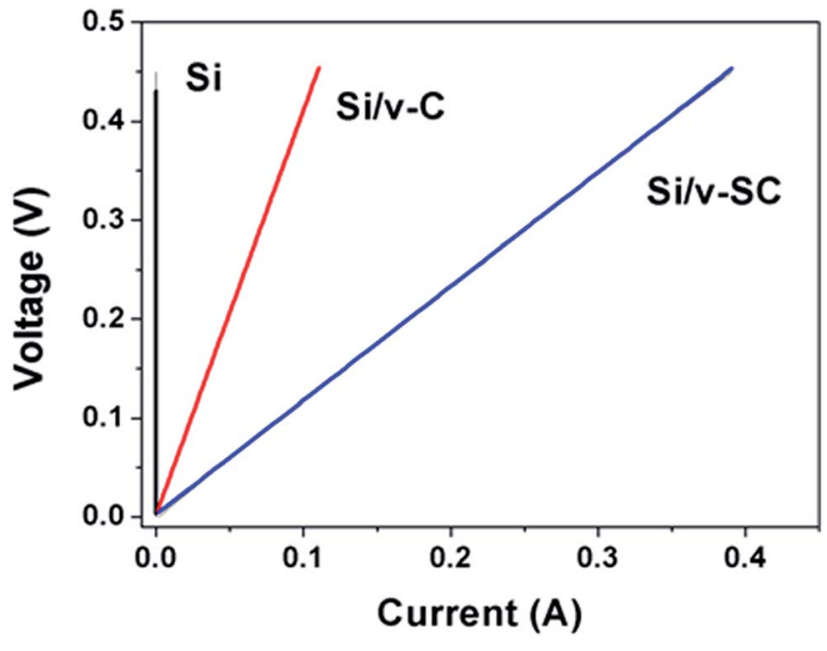

Fig. $8 \quad I-V$ curves of $\mathrm{Si}, \mathrm{Si} / \mathrm{v}-\mathrm{C}$ and $\mathrm{Si} / \mathrm{v}-\mathrm{SC}$.

lithiation process, which could be mainly attributed to the formation of SEI layer on the surface of carbon shell. ${ }^{32}$ Fig. $9 \mathrm{~b}$ shows the cycling performance of all the samples as anode at a current density of $0.4 \mathrm{~A} \mathrm{~g}^{-1}$. Si, Si/v-C and $\mathrm{Si} / \mathrm{v}-\mathrm{SC}$ electrode exhibited an initial discharge capacity of 3194, 1793 and 1339 $\mathrm{mA} \mathrm{h} \mathrm{g}^{-1}$, with an initial $\mathrm{CE}$ of $70.8,64.3$ and $83.9 \%$, respectively. Compared with the $\mathrm{Si} / \mathrm{v}-\mathrm{C}$, the $\mathrm{Si} / \mathrm{v}-\mathrm{SC}$ with $\mathrm{S}$-doping exhibited a higher initial $\mathrm{CE}$, indicating that the S-doping facilitate improving the $\mathrm{CE}$ during the first lithiation/ delithiation process. The capacity of $\mathrm{Si}$ electrode degraded quickly due to the cracking and pulverization of the Si nanoparticles. As a comparison, $\mathrm{Si} / \mathrm{v}-\mathrm{C}$ showed an improved cyclability, retaining a reversible capacity of $827 \mathrm{~mA} \mathrm{~h} \mathrm{~g}^{-1}$ after 105 cycles. Notably, Si/v-SC exhibited the best cycling stability, showing a reversible capacity of $1120 \mathrm{~mA} \mathrm{~h} \mathrm{~g}{ }^{-1}$ (90\% capacity retention) after 105 cycles and a capacity of $664 \mathrm{~mA} \mathrm{~h} \mathrm{~g}^{-1}$ even after 300 cycles with a small capacity fading rate of $0.1 \%$ per cycle. The excellent cycling stability can be attributed to the confinements of the S-doped carbon shell with a buffering space which efficiently accommodate the mechanical stress induced by the severe volume variation of Si particles over cycling. As shown in Fig. 9c, $\mathrm{Si} / \mathrm{v}-\mathrm{C}$ displayed a relatively fast capacity decrease from $1616 \mathrm{~mA} \mathrm{~h} \mathrm{~g}^{-1}$ at $0.2 \mathrm{~A} \mathrm{~g}^{-1}$ to $430 \mathrm{~mA} \mathrm{~h} \mathrm{~g}^{-1}$ at $10 \mathrm{~A}$ $\mathrm{g}^{-1}$. Compared with $\mathrm{Si} / \mathrm{v}-\mathrm{C}, \mathrm{Si} / \mathrm{v}-\mathrm{SC}$ showed better rate performance, retaining a reversible capacity of 1384 and $537 \mathrm{~mA} \mathrm{~h} \mathrm{~g}^{-1}$ at $0.2 \mathrm{~A} \mathrm{~g}^{-1}$ and $10 \mathrm{~A} \mathrm{~g}^{-1}$. Notably, when the current density returned back to $0.2 \mathrm{~A} \mathrm{~g}^{-1}$, a reversible capacity of $1160 \mathrm{~mA} \mathrm{~h}$ $\mathrm{g}^{-1}$ was retained ( $83.8 \%$ of the initial charge capacity). The high reversible capacities and remarkable rate performance of $\mathrm{Si} / \mathrm{v}$ SC facilitate its utilization in next generation high-power LIBs.

To better understand the effect of the S-doped-carbon shell on the lithiation/delithiation process of $\mathrm{Si} / \mathrm{v}-\mathrm{SC}, \mathrm{CV}$ and EIS measurements were performed. Fig. 10a and b compared the Nyquist plots of $\mathrm{Si}$ and $\mathrm{Si} / \mathrm{v}$-SC electrode before and after 20 cycles. These Nyquist plots were fitted with the equivalent circuit shown in Fig. 10c. This circuit consists of an independent resistor $\left(R_{\mathrm{c}}\right)$, two resistors with constant phase elements (CPE) in parallel and a Warburg diffusion element to account for electrolyte/electrode
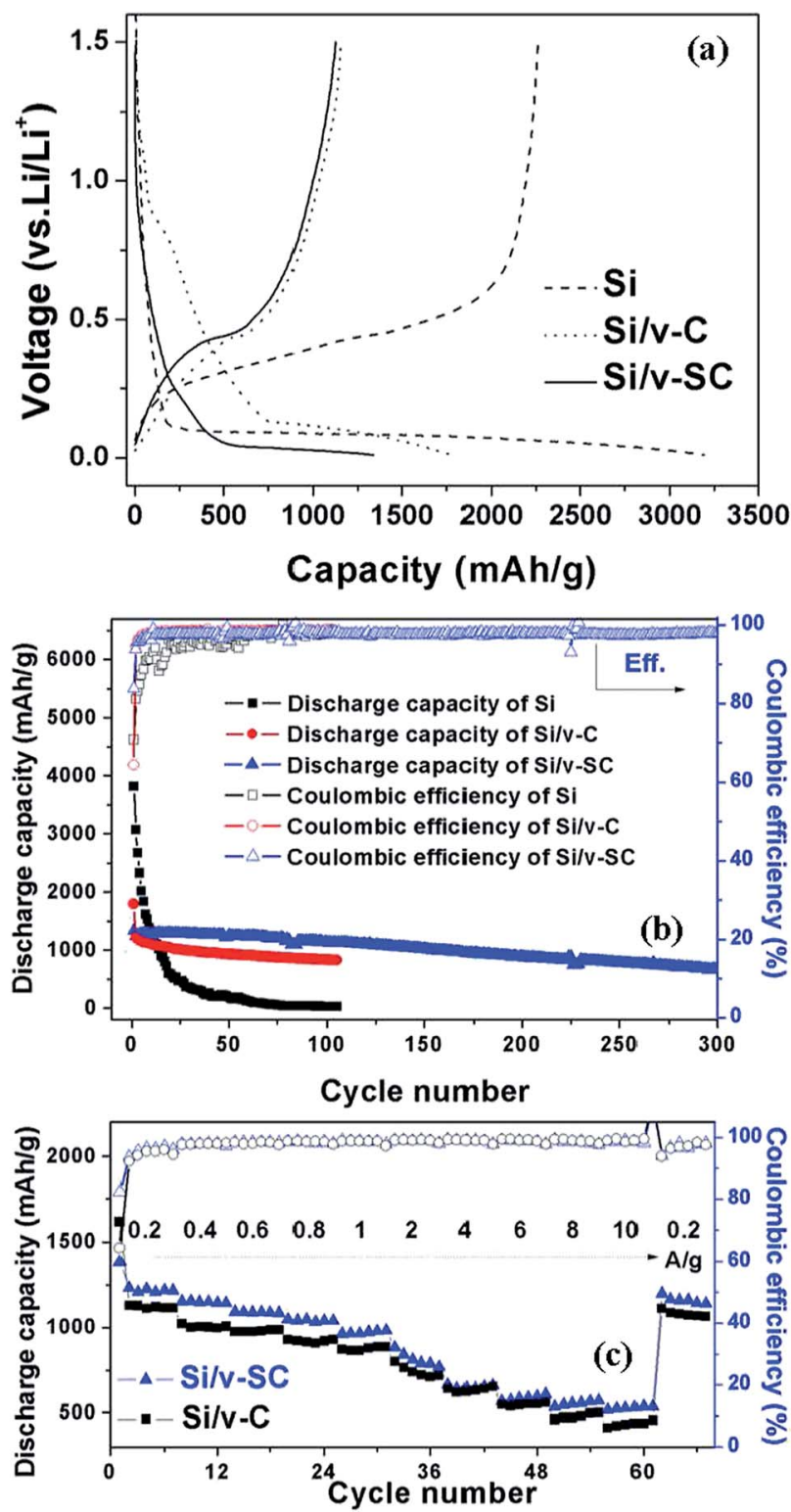

Fig. 9 Galvanostatic charge/discharge profiles of the initial cycle of the $\mathrm{Si}, \mathrm{Si} / \mathrm{v}-\mathrm{C}$ and $\mathrm{Si} / \mathrm{v}-\mathrm{SC}$ electrode (a). Cycling performance and coulombic efficiency of the samples (b). Rate capability of the Si, Si/v-C and $\mathrm{Si} / \mathrm{v}$-SC electrode (c).

resistance $\left(R_{\mathrm{e}}\right)$, SEI film resistance $\left(R_{\mathrm{sf}}\right)$ and charge transfer resistance $\left(R_{\mathrm{ct}}\right)$. The Si/v-SC electrode showed much smaller value and the value change of charge-transfer resistant $\left(R_{\mathrm{ct}}\right)$ before cycling and after 20 cycles $\left(R_{\mathrm{ct}}\right.$ (before) $=30 \Omega ; R_{\mathrm{ct}}=22 \Omega$ ), as compared with that of $R_{\mathrm{ct}}$ (before) $=63 \Omega ; R_{\mathrm{ct}}=95 \Omega$ for the Si electrode.

Fig. 11 showed the $\mathrm{CV}$ curves of $\mathrm{Si}$ and $\mathrm{Si} / \mathrm{v}-\mathrm{SC}$ electrode recorded at first 5 cycles from $10 \mathrm{mV}$ to $1.5 \mathrm{~V}$. Both of the first discharge process for $\mathrm{Si}$ (Fig. 11, insert) and Si/v-SC showed a weak peak around 1.2-1.0 $\mathrm{V}$ and a sharp reduction peak below $0.3 \mathrm{~V}$, which can be attributed to the formation of SEI layer and the insertion of $\mathrm{Li}^{+}$into $\mathrm{Si}$ host, respectively. ${ }^{32,33}$ In the subsequent charge process, two broad peaks appeared at 0.39 and $0.53 \mathrm{~V}$, corresponding to the decomposition of the $\mathrm{Li}_{x} \mathrm{Si}$ and the extraction process of $\mathrm{Li}^{+}$from the $\mathrm{Si}$ host, respectively. In the 

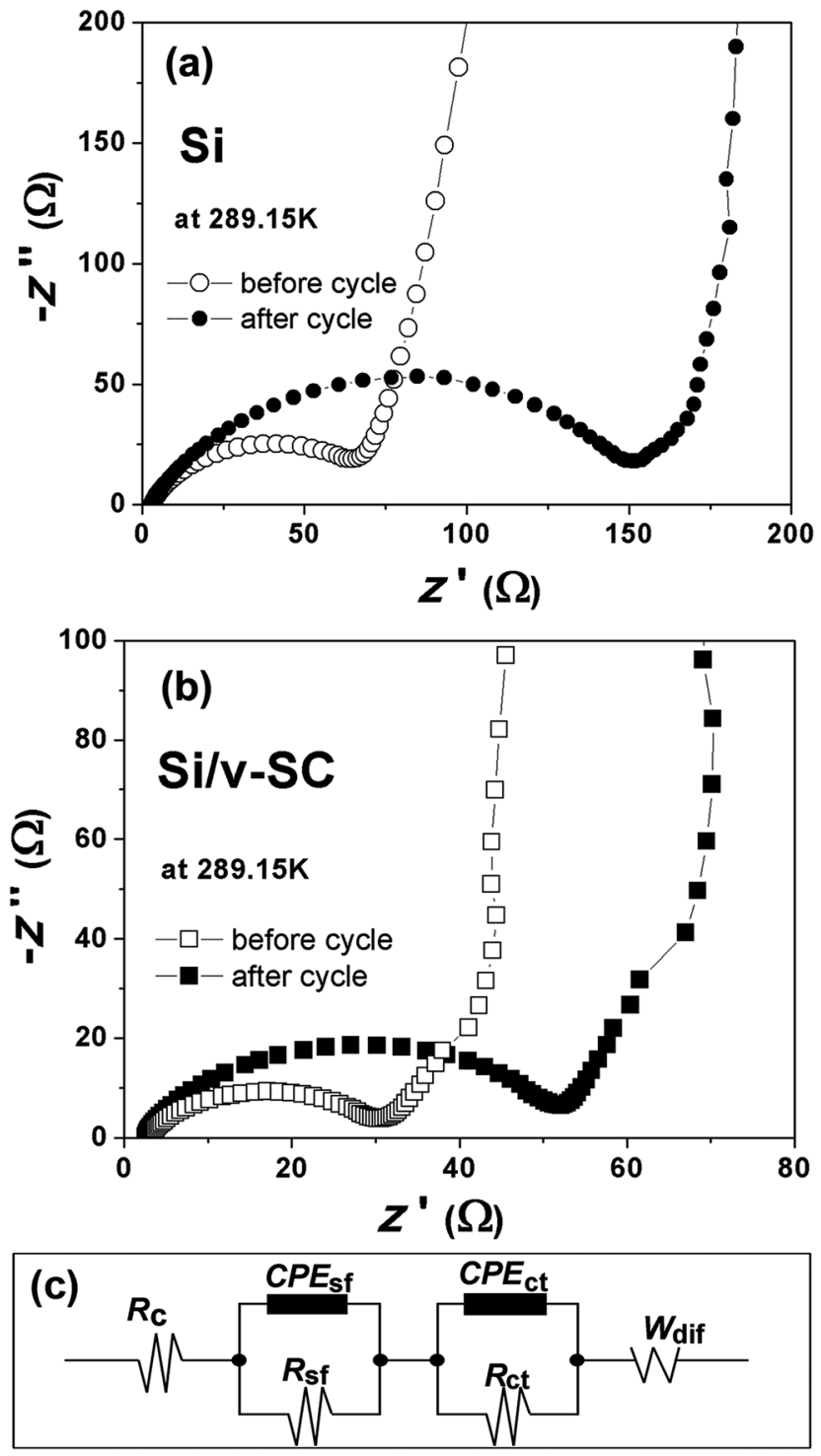

Fig. 10 Nyquist plots of $\mathrm{Si}(\mathrm{a})$ and $\mathrm{Si} / \mathrm{v}$-SC (b) electrodes before and after 20 cycles. The equivalent circuit used to model the impedance spectra in (a) and (b) (c).

following cycles, the cathodic peak around 1.2-1.0 V disappeared and the cathodic peak at $0.2 \mathrm{~V}$ gradually evolved. The characteristic peaks became more pronounced with the increase of scan times, mainly due to the activation of more Si phase during lithiation/delithiation process. ${ }^{34}$ Compared with the Si electrode, after the first cycle, CV curves of $\mathrm{Si} / \mathrm{v}-\mathrm{SC}$ electrode showed no significant shift, suggesting an enhanced cycling performance. The EIS and CV analysis demonstrates that the Si/v-SC composite with the buffering void typed S-doped carbon shell exhibits a more favorable electrochemical kinetics, thus a much improved electrochemical performances compared with the Si electrode.

\section{Effects of S-doping}

In order to investigate the effects of S-doping on the properties of carbon matrix, S-doped carbon materials (SC-1, SC-2, SC-3, SC-4 and SC-5) with different S-doping contents were

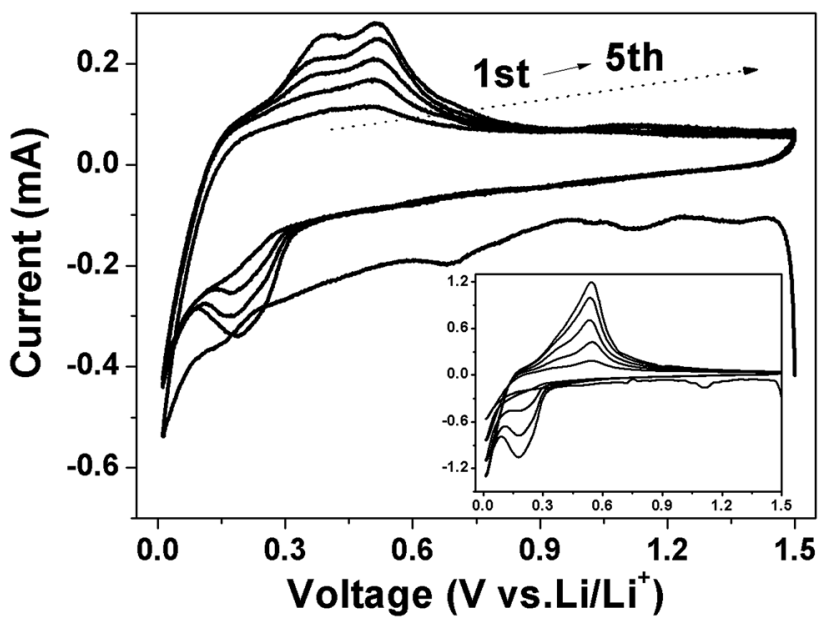

Fig. $11 \mathrm{CV}$ curves of Si (insert) and Si/v-SC electrode from $1.5 \mathrm{~V}$ to $0.01 \mathrm{~V}$ at a scan rate of $0.2 \mathrm{mV} \mathrm{s}^{-1}\left(\mathrm{vs}\right.$. $\left.\mathrm{Li} / \mathrm{Li}^{+}\right)$.

prepared. EDS analysis showed that three different elements, C, $\mathrm{O}$ and S, exist for the SC-2, SC-3, SC-4 and SC-5 sample (Fig. 12a). The weight ratio of S in the SC-2, SC-3, SC-4 and SC-5 sample was $0.97,1.99,3.83$ and $5.54 \mathrm{wt} \%$, respectively.

Fig. 12b presents the cycling performance of SC-2, SC-3, SC-4 and SC-5 samples. The SC- 1 electrode showed a relatively high initial discharge capacity of $1550 \mathrm{~mA} \mathrm{~h} \mathrm{~g}^{-1}$ with a very low initial CE of $19 \%$. And, the discharge capacity quickly decreased to $320 \mathrm{~mA} \mathrm{~h} \mathrm{~g}^{-1}$ at second cycle. After S-doping, SC-2, SC-3, SC-4 and SC-5 electrode showed improved reversible capacity and initial $\mathrm{CE}$ of $35,32,52$ and $50 \%$, respectively (Table 1). The initial CE of carbon electrode generally increased with increase of the $S$ content, and saturated when the content of $S$ reaches a value of $3.84 \mathrm{wt} \%$ (Fig. 12b, insert).

Raman and XRD measurement were conducted to investigate the effects of S-doping on the structure of carbon. As shown in Fig. 12c, the characteristic peak of $\mathrm{S}=\mathrm{O}$ bond at $1163 \mathrm{~cm}^{-1}$
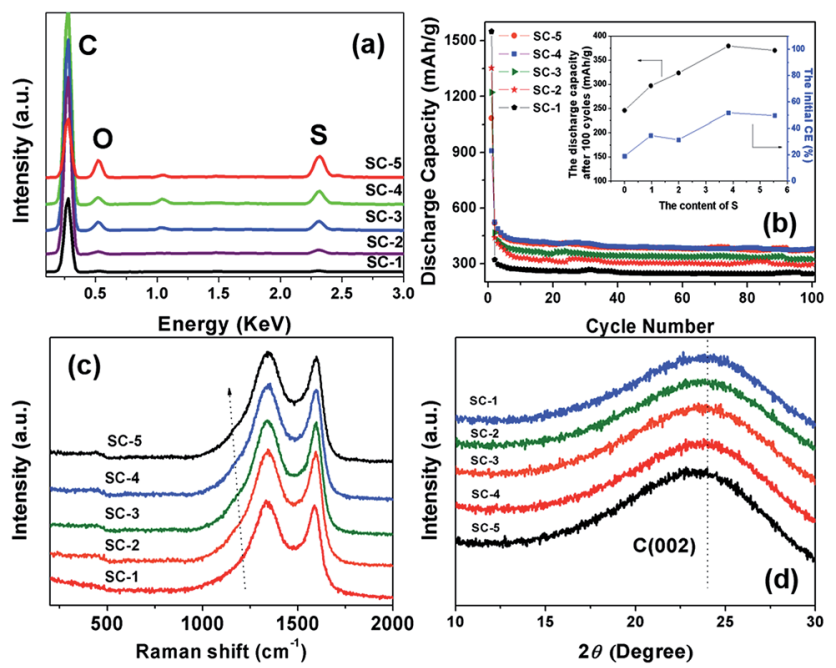

Fig. 12 EDS spectra (a), electrochemical performance (b), Raman spectrum (c), and XRD patterns (d) of SC-1, SC-2, SC-3, SC-4 and SC-5. 
Table 1 The weight content of $S, d_{(002)}, I_{D} / I_{G}$, initial CE (Eff.1st), of SC-1, SC-2, SC-3, SC- 4 and SC-5

\begin{tabular}{lllll}
\hline Samples & Content of S $(\%)$ & $d_{(002)}(\AA)$ & $I_{\mathrm{D}} / I_{\mathrm{G}}$ & Eff. 1 st \\
\hline SC-1 & 0.00 & 3.5297 & 1.022 & $19 \%$ \\
SC-2 & 0.97 & 3.5394 & 1.040 & $35 \%$ \\
SC-3 & 1.99 & 3.5504 & 1.068 & $32 \%$ \\
SC-4 & 3.83 & 3.5595 & 1.082 & $52 \%$ \\
SC-5 & 5.54 & 3.5615 & 1.102 & $50 \%$
\end{tabular}

was clearly observed in the Raman spectra for SC-2, SC-3, SC-4 and SC-5, indicating the $\mathrm{S}$ doping in these samples. ${ }^{27,28}$ The characteristic peak of the D and G band of carbon at 1340 and $1580 \mathrm{~cm}^{-1}$ was observed in all the samples, typical for amorphous carbon and crystalline graphite, respectively. ${ }^{24}$ The intensity ratio of $\mathrm{D} / \mathrm{G}$ band $\left(I_{\mathrm{D}} / I_{\mathrm{G}}\right)$ for all the samples was shown in Table 1 . The value of $I_{\mathrm{D}} / I_{\mathrm{G}}$ increased with increase of the $\mathrm{S}$ content in these S-doped carbon samples, and thus the increased amorphous character.

After S-doping, the XRD peak of the carbon (002) plane for SC-2, SC-3, SC-4 and SC-5 is somewhat downshifted to a lower wavenumber (Fig. 12d). The interspace of carbon (002) crystal face $\left(d_{(002)}\right)$ for all samples was calculated and was shown in Table 1 . The distance of carbon crystal face increased with increase of the $\mathrm{S}$ content in these S-doped carbon samples, primarily due to the doping of $\mathrm{S}$ atom with larger atomic diameter $(2.04 \AA)$ in the carbon matrix. The carbon interlayer with increased distance in anode material can increase the reversibility of lithiation/delithiation of the cells, which have a favorable effect on improving the electrochemical performance of the carbon material. ${ }^{35}$

\section{Conclusions}

The Si/S-doped carbon with buffering voids composite (Si/v-SC) was prepared by a facile hydrothermal reaction of glucose and simultaneously chemical polymerization of S-containing monomer EDOT in the presence of $\mathrm{Si} @ \mathrm{SiO}_{2}$ nanoparticles, followed by carbonization and removal of the $\mathrm{SiO}_{2}$ template layer. The $\mathrm{Si}$ nanoparticles were embedded in the S-doped carbon buffer space to form a core-shell structure. Compared to the $\mathrm{Si}$ /carbon composite without the S-doping $(\mathrm{Si} / \mathrm{v}-\mathrm{C})$, the $\mathrm{Si} /$ v-SC composite electrode showed improved conductivity, cycling and rate performance, exhibiting a reversible capacity of $664 \mathrm{~mA} \mathrm{~h} \mathrm{~g}{ }^{-1}$ over 300 cycles at the current of $0.4 \mathrm{~A} \mathrm{~g}^{-1}$ and a high capacity of $537 \mathrm{~mA} \mathrm{~h} \mathrm{~g}^{-1}$ even at $10 \mathrm{~A} \mathrm{~g}^{-1}$. XRD and Raman test revealed that the S-doping increased the interspace of carbon crystal face, and improved the amorphous structure of carbon and thus the initial coulombic efficiency.

\section{Acknowledgements}

This work was supported by the National Natural Science Foundation of China (21573239), Guangdong Provincial Project for Science \& Technology (2014TX 01N014/2014A050503050/ 2015B010135008), Guangzhou Municipal Project for Science \&
Technology (2014Y2-00219/201509010018). LZ thanks K. C. Wong Education Foundation for support.

\section{References}

1 X. Zhao, M. J. Li, N. Ross and Y. M. Lin, RSC Adv., 2016, 6, $77682-77687$.

2 C. Liu, F. Li, L.-P. Ma and H. M. Cheng, Adv. Mater., 2010, 22, E28.

3 H. Wu and Y. Cui, Nano Today, 2012, 7, 414-429.

4 H. Kim, M. Seo, M. H. Park and J. Cho, Angew. Chem., Int. Ed., 2010, 49, 2146-2149.

5 C. Zhang, L. Gu, N. Kaskhedikar, G. Cui and J. Maier, ACS Appl. Mater. Interfaces, 2013, 5, 12340-12345.

6 P. Zhang, L. Wang, J. Xie, L. Su and C. A. Ma, J. Mater. Chem. A, 2013, 2, 3776-3782.

7 J. Lee and S. Noda, RSC Adv., 2015, 5, 2938-2946.

8 J. R. Szczech and S. Jin, Energy Environ. Sci., 2011, 4, 56-72.

9 L. W. Su, Z. Zhou and M. M. Ren, Chem. Commun., 2010, 46, 2590-2592.

10 L. Su, Y. Jing and Z. Zhou, Nanoscale, 2011, 3, 3967-3983.

11 J. S. Bridel, T. Azais, M. Morcrette, J. M. Tarascon and D. Larcher, Chem. Mater., 2010, 22, 1229-1241.

12 H. Wang, J. Xie, S. C. Zhang, G. S. Cao and X. B. Zhao, RSC Adv., 2016, 6, 69764-69772.

13 Y. S. Hu, R. Demir-Cakan, M. M. Titirici, J. O. Mueller, R. Schloegl, M. Antonietti and J. Maier, Angew. Chem., Int. Ed., 2008, 47, 1645-1649.

14 C. Du, M. Chen, L. Wang and G. Yin, J. Mater. Chem., 2011, 21, 15692-15697.

15 S. Iwamura, H. Nishihara and T. Kyotani, J. Phys. Chem. C, 2012, 116, 6004-6011.

16 L. Su, J. Xie, Y. Xu, L. Wang, Y. Wang and M. Ren, Phys. Chem. Chem. Phys., 2015, 17, 17562-17565.

17 S. Chen, M. L. Gordin, R. Yi, G. Howlett, H. Sohn and D. Wang, Phys. Chem. Chem. Phys., 2012, 14, 12741-12745.

18 L. Yue, W. Zhang, J. Yang and L. Zhang, Electrochim. Acta, 2014, 125, 206-217.

19 Y. Wang, F. Su, C. D. Wood, J. Y. Lee and X. S. Zhao, Ind. Eng. Chem. Res., 2008, 47, 2294-2300.

20 W. Kicinski, M. Szala and M. Bystrzejewski, Carbon, 2014, 68, 1-32.

21 L. Yue, S. Wang, X. Zhao and L. Zhang, J. Mater. Chem., 2012, 22, 1094-1099.

22 L. Yue, H. Zhong, D. Tang and L. Zhang, J. Solid State Electrochem., 2013, 17, 961-968.

23 M. L. Terranova, S. Orlanducci, E. Tamburri, V. Guglielmotti and M. Rossi, J. Power Sources, 2014, 246, 167-177.

24 D. Shao, D. Tang, Y. Mai and L. Zhang, J. Mater. Chem. A, 2013, 1, 15068-15075.

25 H. S. Zhou, S. M. Zhu, M. Hibino, I. Honma and M. Ichihara, Adv. Mater., 2003, 15, 2107.

26 S. Garreau, J. L. Duvail and G. Louarn, Synth. Met., 2001, 125, 325-329.

27 C. H. Choi, S. H. Park and S. I. Woo, Green Chem., 2011, 13, 406-412.

28 L. Zhang, J. Niu, M. Li and Z. Xia, J. Phys. Chem. C, 2014, 118, 3545-3553. 
29 J. Liu, Q. Zhang, Z. Y. Wu, J. T. Li, L. Huang and S. G. Sun, ChemElectroChem, 2015, 2, 611-616.

30 W. Li, Y. Tang, W. Kang, Z. Zhang, X. Yang, Y. Zhu, W. Zhang and C. S. Lee, Small, 2015, 11, 1345-1351.

31 B. Zhang, Z. L. Xu, Y. B. He, S. Abouali, M. A. Garakani, E. K. Heidari, F. Kang and J. K. Kim, Nano Energy, 2014, 4, 88-96.
32 A. J. Gmitter, I. Plitz and G. G. Amatucci, J. Electrochem. Soc., 2012, 159, A370-A379.

33 Y. Zhu, W. Liu, X. Zhang, J. He, J. Chen, Y. Wang and T. Cao, Langmuir, 2013, 29, 744-749.

34 Y. Xu, G. Yin, Y. Ma, P. Zuo and X. Cheng, J. Mater. Chem., 2010, 20, 3216-3220.

35 Y. P. Wu, S. Fang, Y. Jiang and R. Holze, J. Power Sources, 2002, 108, 245-249. 